\title{
Study on Quantitative Evaluation on Management modernization of Tongzhou Sub-center City in Beijing
}

\author{
Wei LIU ${ }^{1, a}$, Shu-xia LEl ${ }^{2, b}$, Shi-yun ZHANG ${ }^{3, c}$ \\ ${ }^{1}$ School of Business, North China Institute of Science and Technology, Beijing, China \\ ${ }^{2}$ Beijing Research for Science of Science, Beijing, China \\ ${ }^{3}$ Beijing Research for Science of Science, Beijing, China \\ alwbj0506@163.com, bleishuxia2000@163.com, czhangshiyun@vip.sina.com
}

\begin{abstract}
Key words: Urban sub-center; urban modernization; management modernization; innovation of urban management

Abstract: The selection and evaluation of urban management modernization indicators should be coordinated with the urban management system as a whole. Through the expert method to explore various influencing factors of modern city management, using the Delphi method divides these factors into city management modernization of the concept of city management system, city modernization management means and methods of modernization, modernization of city management benefit four main factors, namely the level indicators, and then use the brainstorming and Delphi method to select two indicators and weights. By applying the fuzzy comprehensive evaluation theory and method, the quantitative and comprehensive evaluation of urban management modernization and construction is carried out. According to this method, to considering the various factors affecting the level of modernization of city management, the evaluation of indicators of factors were quantified by using expert scoring method, and to make a scientific and reasonable assessment of modern city management and construction, find deficiencies in the management of the city modernization, and points out the countermeasures and measures should be taken. Provide fundamental basis for the development of city modernization management policy of the government.
\end{abstract}

\section{Introduction}

Construction management modernization evaluation index system of Beijing Tongzhou District sub center should take the construction of "Beijing new city" as the goal, efforts to improve the quality and efficiency of sub center economic growth, to improve people's living standards and people-oriented as the fundamental starting point to the institutional innovation and scientific and technological progress as the driving force, enhance the development of comprehensive coordination sustainability; adhere to construction of reality from the Beijing city center of Tongzhou District, adhere to the urban and rural areas, with the industrialization and urbanization and city to promote industrialization, accelerating urban-rural integration and modernization, the construction of the new Tongzhou comprehensive coordinated and sustainable development, seize the favorable position in the pattern of regional development, the establishment of higher reference system and the goal; adhere to strengthen institutional innovation, strengthen scientific and technological innovation, and actively promote the city social management innovation, strive to open Create a new situation in the scientific development of the sub - center of Beijing and Tongzhou District, and contribute to the basic modernization of Beijing[1]. First, the implementation of the first time to complete, to build the basic framework of the new city of Beijing. With ten years or so, Tongzhou will be built into a new city of Beijing; The second is that the level of development is relatively high, and by the end of 14th Five-Year, it has reached the level of developed countries in the world.

Third, the innovation takes the lead. Take the lead in promoting the transformation of the mode of economic development, must be based on innovation and development as a driving force, to explore, through innovative thinking, open up a new path of modernization center, make a 
contribution to the country out of a sub center of the characteristics of the times, in line with national modernization Chinese Deputy Center road $[2,3]$.

\section{Establishment and establishment of hierarchy structure of urban management modernization index weight}

\section{Set up factor sets}

In the evaluation of city management modernization, from the point of view of modern city management as a whole, the main factors affecting the modern city management is divided into: the city management concept of modernization, city management system, city modernization management means and methods of city modernization and management modernization of 4 kinds of benefits, Respectively with $u_{1}{ }^{(1)} 、 u_{2}{ }^{(1)} 、 u_{3}{ }^{(1)} 、 u_{4}{ }^{(1)}$ representative. These 4 factors constitute the evaluation factors of urban management modernization $U$, factor group $n=4$. Namely $U=\left\{u_{1}{ }^{(1)}\right.$, $\left.u 2^{(1)}, u 3^{(1)}, u 4^{(1)}\right\}$.

$$
\begin{aligned}
& u_{1}=\left\{u_{11}{ }^{(2)}, u_{12}{ }^{(2)}, u_{13}{ }^{(2)}, u_{14}{ }^{(2)}, u_{15^{(2)}}\right\} ; u_{2}=\left\{u_{21}{ }^{(2)}, u_{22}{ }^{(2)}, u_{23}{ }^{(2)}, u_{24}{ }^{(2)}, u_{25} 5^{(2)}, u_{26}{ }^{(2)}\right\} \\
& u_{3}=\left\{u_{31}{ }^{(2)}, u_{32}{ }^{(2)}, u_{33}{ }^{(2)}, u_{34}{ }^{(2)}, u_{35}{ }^{(2)}, u_{36}{ }^{(2)}, u_{37}{ }^{(2)}, u_{38}{ }^{(2)}, u_{39}{ }^{(2)}\right\} ; u_{4}=\left\{u_{41}{ }^{(2)}, u_{42}{ }^{(2)}, u_{43}{ }^{(2)}, u_{44}{ }^{(2)}\right. \text {, }
\end{aligned}
$$

$\left.u 45^{(2)}, u 46^{(2)}, u 47^{(2)}\right\}$

In formula: $u_{11}{ }^{(2)}$ stands for human centered concept, $u_{12}{ }^{(2)}$ stands for system management concep, $u_{13}{ }^{(2)}$ stands for rule of law concept, $u_{14}{ }^{(2)}$ stands for market concept, $u_{15}{ }^{(2)}$ represents sustainable development concept; $u_{21}{ }^{(2)}$ on behalf of the government management system modernization, $u_{22}{ }^{(2)}$ on behalf of the city government management system modernization, $u_{23}{ }^{(2)}$ on behalf of the city management law, $u_{24}{ }^{(2)}$ modern operation and decision-making mechanism, $u_{25}{ }^{(2)}$ on behalf of the city management participation system modernization, $u_{26}{ }^{(2)}$ on behalf of the public participation in multi city; $u_{31}{ }^{(2)}$ on behalf of a modern city planning, $u_{32}{ }^{(2)}$ on behalf of the city management information, $u_{33}{ }^{(2)}$ modern management methods, $u_{34}{ }^{(2)}$ modern city management technology, $u_{35}{ }^{(2)}$ on behalf of the community service function, $u 36^{(2)}$ on behalf of the function of community autonomy, $u 37^{(2)}$ on behalf of the community leadership construction, $u 38^{(2)}$ on behalf of the city management performance evaluation results, $u 39^{(2)}$ on behalf of the city management performance evaluation results; $u 41^{(2)}$ on behalf of the city function and the image, $u 42^{(2)}$ on behalf of the city economic development level, $u_{43}{ }^{(2)}$ on behalf of the city performance management, $u_{44}{ }^{(2)}$ represents the degree of livable city, $u 45^{(2)}$ on behalf of the city ecological environment beautiful, $u_{46}{ }^{(2)}$ on behalf of the city social security, $u 47^{(2)}$ on behalf of the city residents' satisfaction.

\section{Establish the weight set: determine the weights of the evaluation index of the modernization of the city management}

The weight set is the importance of the lower evaluation index to the upper level index. The weights of each sub factor can be determined according to the subordinate degree of each factor $u_{i j}{ }^{(2)}$ to the main factor $u_{i}{ }^{(1)}(i=1,2, \ldots, m ; j=1,2, \ldots, n)$. The $u_{i j}{ }^{(2)}$ weighting set of each factor is $A_{i}=\left(a_{i 1}\right.$, $\left.a_{i 2}, \ldots, a_{i n}\right), a_{i j}$ meets $a_{i j} \geq 0, \quad \sum_{j=1}^{n} a_{i j}=1$.

Then, according to each main factor $u_{i}^{(1)}(i=1,2, \ldots, m)$, the importance of the overall urban management modernization by giving each principal factor an appropriate weighting of $a_{i}(i=1$, $2, \ldots, m)$, then the factor class weight sets $A=\left(a_{1}, a_{2}, a_{3}, a_{4}\right)=\left(\begin{array}{lll}0.15, & 0.25,0.36, & 0.24\end{array}\right)$. There are many methods to determine weights, such as Delphy Fa, analytic hierarchy process (AHP method) and "0-4" scoring method, etc.. This paper selects Delphy Fa analysis and AHP method, in a number of experts in the management of the city's long-term work, the main factors were, influence on modern city management sub factors and weights of evaluation conducted by them, and then standardized. In this weight distribution despite the subjective factor influence, if the same evaluation factors with different weights while the conclusions are different; however, multi-level 
evaluation to the subjective factor within the limits of a single small area, can make the difference between subjective and objective factors is reduced, consistent thus, to ensure the accuracy and reliability of the evaluation results[4-6].

\section{Create alternative sets (evaluation sets)}

Beijing Tongzhou sub central city management modernization comprehensive evaluation index is divided into 5: $\mathrm{V}=$ \{excellent, good, medium, and poor, and the difference is quantified as $\{0.95$, $0.85,0.75,0.65,0.45\}$. Table 1 is the fuzzy comprehensive evaluation system of Beijing city management modernization.

\section{Fuzzy comprehensive evaluation of urban management modernization}

The fuzzy comprehensive evaluation of the urban management modernization of multi-level system starts from the lowest level and makes a multi-level and comprehensive evaluation from the top to the bottom, and gets the comprehensive evaluation result of the original problem until the highest level. Among them, the evaluation index vector of the evaluation factor of layer $\mathrm{K}$ is the membership degree of the evaluation index of layer k-1. In Table 1, sub factors can also be subdivided into the lower layers. This paper only three grade comprehensive evaluation sub factors and main factors, sub factors comprehensive evaluation of multilayer down and so on. $\widetilde{R}_{1}, \widetilde{R}_{2}$, $\widetilde{R}_{3}, \widetilde{R}_{1}$, respectively, $u 1^{(1)}, u 2^{(1)}, u 3^{(1)}, u 4^{(1)}$ single factor judgment matrix. The result of single factor evaluation is calculated by fuzzy transformation $\tilde{B}=\tilde{A} \circ \tilde{R}$.

\section{Comprehensive Evaluation Basic Model of Urban Management Modernization}

For the modern city management is concerned, although the influence of various factors on the importance of modern city management there are some differences in the size of its weight value is different, but their influence on the evaluation and optimization of modern city management is indispensable. This requires the fuzzy matrix composite operation, all factors according to the weight of the size must be balanced, taking into account the influence of city management modernization; therefore, the weighted average method in the evaluation of the degree of modern city management timely". Second stage comprehensive evaluation model: $\widetilde{B}_{i j}=\widetilde{A}_{i j}$ o $\widetilde{R}_{i j}$; First stage comprehensive evaluation model: $\widetilde{B}_{i}=\widetilde{A}_{i}$ o $\widetilde{R}_{i}$; Comprehensive index evaluation model: $\widetilde{B}=\widetilde{A} \circ \widetilde{R}$.

$$
\text { Among them, } b_{j}=\sum_{i=1}^{m} a_{i} r_{i j} ; \sum_{j=1}^{n} b_{j}=\sum_{j=1}^{n} \sum_{i=1}^{m} a_{i} r_{i j} ; \quad V=\sum_{i=1}^{m} b_{i} v_{i} / \sum_{i=1}^{m} b_{i}
$$

\section{Fuzzy comprehensive evaluation at all levels}

For the final division of multiple evaluation $\operatorname{spaces}\left(u_{i j}{ }^{(1)}, V, \tilde{R}_{i j}\right), 2$ levels of fuzzy comprehensive evaluation, 1 levels of comprehensive evaluation and comprehensive evaluation are conducted. Here $\tilde{R}_{i j}$ is a single factor evaluation matrix about the factor set $u_{i j}{ }^{(1)}$. The three comprehensive evaluation analyses are as follows.

-Two level comprehensive evaluation. (1) the concept of people-oriented evaluation value is: 0.855 , the evaluation is good; (2) system management concept of evaluation value is: 0.720 , the evaluation is medium; (3) the concept of the rule of law degree evaluation value is: 0.780 , the evaluation for the medium; (4) the concept of market evaluation value: 0.705 , evaluation medium; (5) the concept of sustainable development degree evaluation value: 0.730, evaluation for medium; (6) the government management system modernization evaluation value is: 0.695 , the evaluation for the pass +; (7) the city government management system modernization evaluation value: 0.615 , evaluation for the pass; (8) the city management law evaluation value: 0.625 , evaluation for the pass; (9) operation and decision-making mechanism of modernization evaluation value: 0.655 , evaluation for the pass; (10) to participate in city management system modernization evaluation value is: 0.725 , 
the evaluation is medium; (11) city public participation in multi degree evaluation value: 0.585 , evaluation failed; (12) a modern city planning evaluation value: 0.840 , evaluation is good; (13) evaluation of city management informatization value: 0.815 , evaluation is good; (14) modern management methods evaluation value: 0.640. The evaluation for the pass; (15) the city management modernization evaluation value is: 0.815 , the evaluation is good; (16) to evaluate the function of community service value: 0.820 , evaluation is good; (17) the function of community autonomy evaluation value: 0.760 , evaluation for the medium; (18) the construction work of the evaluation value of community leaders: 0.860 , the evaluation is good; (19) evaluate the quality of management personnel value: 0.705 , evaluation is medium; (20) the city management performance evaluation performance evaluation value: 0.585 , evaluation for fail $+;(21)$ the city function and image evaluation value: 0.665, evaluation for the pass; (22) evaluation of city economic development level value: 0.675 , evaluation for the pass; (23) city performance management degree (\%) value: 0.635 , evaluation for the pass; (24) city livability (\%) the evaluation value is: 0.765 , evaluation for the medium; (25) the city ecological environment beautiful degree (\%) value: 0.795 , evaluation for the medium; (26) the city social security degree (\%) value: 0.835 , evaluation is good; (27) the city residents satisfaction value: 0.840 , the evaluation is good.

- First level indicators evaluation. Tongzhou sub central city management modernization 4 first level indicators evaluation results: three medium, a pass. The city management concept modernization evaluation value: 0.758 , evaluation for medium city management system; modernization evaluation value: 0.646, evaluation for the pass; city management means and methods of modern evaluation value: 0.76 , evaluation for medium; city management modernization benefit evaluation value: 0.7335 , evaluation: medium, the city the management system of modernization evaluation score too low, this is the bottleneck of Tongzhou District city management modernization in Beijing.

- Comprehensive general index evaluation. From the comprehensive evaluation results, the overall evaluation of the modernization of urban management in Beijing is $V=72.84$, and the evaluation is medium - slightly below the average level (see Table 1). As a whole, the management modernization of Tongzhou Sub-center in Beijing is still below the average level. 
Table 1 The index of the first and two levels of modernized management evaluation of Tongzhou sub central cities

\begin{tabular}{|c|c|c|c|c|c|c|c|c|c|}
\hline First order index & Two level index & weight & Superior & good & middle & pass & Fail & Score & evaluation \\
\hline \multirow{2}{*}{$\begin{array}{l}1 \text { modernization of } \\
\text { urban management }\end{array}$} & (1) the concept of people-oriented & 0.03 & 0.25 & 0.6 & 0.1 & 0.05 & 0 & 0.855 & good \\
\hline & (2) system management concept & 0.03 & 0.05 & 0.25 & 0.35 & 0.2 & 0.15 & 0.720 & middle - \\
\hline concepts $(0.15)$ & (3) degree of rule of law & 0.03 & 0.15 & 0.25 & 0.45 & 0.1 & 0.05 & 0.780 & middle \\
\hline \multirow[t]{2}{*}{ Score 0.758 , } & (4) market concept & 0.03 & 0 & 0.25 & 0.35 & 0.25 & 0.15 & 0.705 & middle - \\
\hline & (5) the concept of sustainable development & 0.03 & 0.15 & 0.2 & 0.25 & 0.25 & 0.15 & 0.730 & middle \\
\hline \multirow{6}{*}{$\begin{array}{l}2 \text { modernization of } \\
\text { urban management } \\
\text { system }(0.25) \\
\text { Score } 0.6458 \text {, Pass }\end{array}$} & $\begin{array}{l}\text { (6) modernization of government } \\
\text { management system }\end{array}$ & 0.03 & 0 & 0.25 & 0.25 & 0.35 & 0.15 & 0.695 & pass + \\
\hline & $\begin{array}{l}\text { (7) Government city management } \\
\text { system modernization }\end{array}$ & 0.05 & 0 & 0.05 & 0.25 & 0.35 & 0.35 & 0.615 & pass - \\
\hline & (8)legalization of urban management & 0.05 & 0 & 0.1 & 0.25 & 0.3 & 0.35 & 0.625 & pass - \\
\hline & $\begin{array}{l}\text { (9)modernization of operation and decision } \\
\text { mechanism }\end{array}$ & 0.04 & 0 & 0.1 & 0.25 & 0.45 & 0.2 & 0.655 & pass \\
\hline & $\begin{array}{l}\text { (10) urban management participation } \\
\text { system modernization }\end{array}$ & 0.04 & 0.1 & 0.15 & 0.35 & 0.3 & 0.1 & 0.725 & middle - \\
\hline & (11) urban public participation & 0.04 & 0 & 0.05 & 0.15 & 0.35 & 0.45 & 0.585 & Fail + \\
\hline \multirow{9}{*}{$\begin{array}{l}3 \text { modernization } \\
\text { of urban } \\
\text { management } \\
\text { means and } \\
\text { methods }(0.36) \\
0.76, \text { medium }\end{array}$} & (12)modernization of urban planning & 0.04 & 0.25 & 0.45 & 0.25 & 0.05 & 0 & 0.840 & good \\
\hline & $\begin{array}{l}\text { (13)urban management means } \\
\text { Informationization }\end{array}$ & 0.04 & 0.2 & 0.3 & 0.45 & 0.05 & 0 & 0.815 & good \\
\hline & $\begin{array}{l}\text { (14)modernization of management } \\
\text { methods }\end{array}$ & 0.04 & 0 & 0.05 & 0.3 & 0.4 & 0.25 & 0.640 & pass \\
\hline & $\begin{array}{l}\text { (15)modernization of urban } \\
\text { management technology }\end{array}$ & 0.04 & 0.2 & 0.3 & 0.45 & 0.05 & 0 & 0.815 & good - \\
\hline & (16)community service function & 0.04 & 0.2 & 0.35 & 0.4 & 0.05 & 0 & 0.820 & good \\
\hline & (17)community autonomy function & 0.04 & 0 & 0.35 & 0.4 & 0.25 & 0 & 0.760 & middle \\
\hline & (18)community leadership construction & 0.04 & 0.35 & 0.45 & 0.15 & 0.05 & 0 & 0.860 & good \\
\hline & (19)quality of managers & 0.04 & 0 & 0.15 & 0.35 & 0.45 & 0.05 & 0.705 & middle - \\
\hline & $\begin{array}{l}\text { (20)urban management achievements } \\
\text { evaluation results }\end{array}$ & 0.04 & 0 & 0.05 & 0.15 & 0.35 & 0.45 & 0.585 & Fail + \\
\hline \multirow{7}{*}{$\begin{array}{l}4 \text { modernization of } \\
\text { urban management } \\
\text { efficiency }(0.24) \\
\text { Score } 0.7335 \text {, } \\
\text { medium. }\end{array}$} & (21)urban function and image degree & 0.04 & 0 & 0.15 & 0.25 & 0.4 & 0.2 & 0.665 & pass \\
\hline & $\begin{array}{l}\text { (22)the level of urban economic } \\
\text { development }\end{array}$ & 0.04 & 0 & 0.15 & 0.25 & 0.45 & 0.15 & 0.675 & pass \\
\hline & (23)urban performance management & 0.04 & 0 & 0.05 & 0.25 & 0.45 & 0.25 & 0.635 & pass \\
\hline & (24)urban living & 0.03 & 0.15 & 0.2 & 0.3 & 0.35 & 0 & 0.765 & middle \\
\hline & (25)urban environmental ecological beauty & 0.03 & 0.2 & 0.25 & 0.35 & 0.2 & 0 & 0.795 & middle \\
\hline & (26)urban social security & 0.03 & 0.2 & 0.45 & 0.35 & 0 & 0 & 0.835 & good \\
\hline & (27)urban residents satisfaction & 0.03 & 0.25 & 0.45 & 0.25 & 0.05 & 0 & 0.840 & good \\
\hline
\end{tabular}

Remarks: the observation values of two indicators are made by several urban management experts and related personnel, each divided into excellent, good, medium, and poor grade. 


\section{Analysis of fuzzy comprehensive evaluation results at all levels}

The two level index evaluation is only a comprehensive evaluation of each small class factor, and the first level index is a comprehensive evaluation of the two level indicators. The specific evaluation, experts also need to consider the comprehensive factors affecting each of the two level indicators, expert knowledge and considering the weight of all factors are different, so playing scores are not the same, it will appear with a two level indicators, expert scoring different values are different, which requires comprehensive evaluation in between classes.

Beijing Tongzhou sub central management modernization comprehensive evaluation results are: Beijing urban management modernization overall level of comprehensive evaluation value: $\mathrm{V}=72.84$ points. As a whole, the management modernization of Tongzhou Sub-center in Beijing is still below the average level.

The evaluation results of the first grade indicators of the modernization of Tongzhou sub central city: 3 indicators are medium, and 1 indicators are pass. The concept of city management modernization evaluation value of 75.8 points, management means and methods of city modernization evaluation value of 76 points, the city management modernization evaluation value of 73.35 points, the 3 indexes for medium and city management system; modernization evaluation value: 0.6458 , evaluation for the pass. According to the evaluation result of the first grade index, the urban management system, system and mechanism of Tongzhou are the biggest short board of the modernization of city management.

- The concept of modern city management (0.758) the main problems: system management concept of (0.72) and the concept of market degree (0.705) of the two index score is too low, this is the effect of foundation of Beijing Tongzhou Sub-center of modern management, management of Tongzhou District city deputy center should establish a system of management and market the concept of strengthening city management and construction.

- The management system of modern city) (0.6458) the main problems of government management system modernization (0.695), the city government management system modernization (0.615), city management law (0.625), modern operation and decision-making mechanism (0.655) and multiple city public participation (0.585) of the five evaluation index score is too low. Just pass the line. And system, system and mechanism of city management is the fundamental factor affecting the city's social and economic development, the government should not only strengthen the construction of Hardware City, should as soon as possible to strengthen the construction of city management software, which is fundamental to modern city management and modernization of the city sustainable development power.

- The modern city management means and methods (0.76) the main problems of modern management methods (0.64) the evaluation value is too low for the pass, the quality of management personnel (0.705) had reached the middle value, city management performance evaluation (0.585), failed + , this shows that Tongzhou city deputy center of modern management means and methods still insufficient.

City management modernization $(0.7335)$ the main problems of city function and the image of (0.665), (0.675) the economic development level of the city, city management of performance (0.635) evaluation scores just over the pass line, the three indicators of a serious drag on the Tongzhou city management efficiency, thereby reducing the level of city management modernization. The scientific orientation of Beijing sub center of Tongzhou city functions and create a new image, and strive to improve the sub center of Tongzhou city economic development level and management level.

\section{Conclusion}

- Fuzzy mathematics is a quantitative method to study and deal with the fuzzy phenomenon, it fully considered quantitatively fuzzy factors, make the evaluation design more practical and reasonable; at the same time, considering the intermediary nature and factors of the system, for the 
modernization of the city, can choose the floating threshold, resulting in a series of different the level of analysis, with a wide range of choice for management decision makers. Using fuzzy comprehensive evaluation method, the analysis of the expert qualitative quantitative results, will not be accurate expression and processing method of digital quantification, reduce subjective factors, improve the scientific and reasonable evaluation and judgment.

- Evaluation of the specific evaluation weight of each factor and single factor matrix value by the experts in the city economic and social management (or expert jury) were studied and discussed, multiple feedback scoring draw according to the actual situation of city management modernization in a certain period, based on quantitative research science, reduced in the evaluation of subjectivity, the results tend to be more objective and fair, the credibility of the relatively strong. Therefore, this method is very scientific, operational and universal.

- The results of the specific evaluation indicators will provide a theoretical basis for strengthening the modernization and construction of urban management. Tongzhou District city deputy center should establish management system management concept and marketing concept to strengthen city management and construction, the government should not only strengthen the construction of Hardware City, should as soon as possible to strengthen the construction of city management system, strengthen the construction of system and mechanism of city management, which is the fundamental factors affecting the social and economic development of the city management modernization and this is the fundamental driving force of modern city management.

\section{Acknowledgement}

This research was financially supported by Beijing Research for Science of Science optional subject "Beijing vice center city modernization management theory and evaluation system research".

\section{References}

[1] Tongzhou District development planning, http://stats.bjtzh.gov.cn/n5244911/n7978319/index.html.

[2] Ji Jianlin. [J]. Jianghai aspect, some thoughts on the basic modernization index system set up $2011,5,15-18$

[3] Zhu Yingming, Yao Shimou, and Ming. Study on the problems of urban modernization index system in China [J]. Human geography, 2000, 8 (in Chinese).

[4] Zhu Qingfang. Comparison of social indicators of world big cities [M]. Beijing: China City Press, 1997, 1-13.

[5] Wu Hanguang. Measurement scale and standard of comfortable living standard in China [J]. Population, China Resources and environment, 1995, 5 (2):57-60.

[6] Liu Wei, Zhang Wei. Quantitative study on the process of urban and rural economic and social integration in Beijing [J]. Ccological economics, 2009, 8 (2):60-63. 